\title{
Effectiveness of a health promotion intervention and education based on Health Belief Model on improving the preventive behaviors of self- Medication among women in Tehran, Iran
}

\section{Negin Niksadat}

Tehran Medical Sciences, I slamic Azad University

Mehrnoosh Akhtari-Zavare

Tehran Medical Sciences, I slamic Azad University

Mahmood Reza Gohari

Iran University of Medical Sciences

Davood Shojae Zadeh

Tehran University of Medical Sciences

Mahnaz Solhi ( $\sim$ Solhi_mahnaz@yahoo.com )

Iran University of Medical Sciences

\section{Research Article}

Keywords: Prevention, Self-Medication, Health Belief Model, Women, Health education \& promotion

Posted Date: March 2nd, 2021

DOI: https://doi.org/10.21203/rs.3.rs-243903/v1

License: (c) (i) This work is licensed under a Creative Commons Attribution 4.0 International License.

Read Full License 
Effectiveness of a health promotion intervention and education based on Health Belief Model on improving the preventive behaviors of self-Medication among women in Tehran, Iran

Negin Niksadat, Mehrnoosh Akhtari-Zavare, Mahmood Reza Gohari, Davood Shojae Zadeh, Mahnaz Solhi

Negin Niksadat (Assistant Professor)

Student Research Committee, Department of Health Education and Promotion, School of Public Health \& safety, Shahid Beheshti University of Medical Sciences, Tehran, Iran.

Department of Public Health, Faculty of health, Tehran Medical Sciences, Islamic Azad University, Tehran, Iran.

Email: neginniksadat@yahoo.com

\section{Mehrnoosh Akhtari- Zavare (Assistant Professor)}

Department of Public Health, Faculty of health, Tehran Medical Sciences, Islamic Azad University, Tehran, Iran.

Email: akhtari_mehrnoosh@yahoo.com

\section{Mahmood Reza Gohari (Associate Professor)}

Department of Statistics \& Mathematics, School of Management \& Health information, Iran University of Medical Sciences, Tehran, Iran.

\section{Davood Shojae Zadeh}

Department of Health Education \& Promotion, School of Health, Tehran University of Medical Sciences, Tehran, Iran.

Mahnaz Solhi (Associate Professor)

(Correspondence)

Department of Health Education \& Promotion, School of Health, Iran University of Medical Sciences, Tehran, Iran.

Email: Solhi_mahnaz@yahoo.com Tel: 09122432363 


\begin{abstract}
Introduction: Self-medication (SM) is used in medicine without consultation with a physician which leads to serious problems, especially in women. This study aimed to investigate the effectiveness of a health promotion intervention and education based on health belief model (HBM) on improving the preventive behaviors of self-Medication among women in Tehran, Iran.

Methods: A quasi-experimental survey was carried out among 88 women in 4 selected health institutions of one of the districts in Tehran, Iran. A multi-stage random sampling method was carried out to select the participants. The intervention group received the educational module based on constructs of HBM on the prevention of SM, free medical facilities, and video about SM. The outcomes were assessed at baseline and one month after intervention by validated questionnaire on constructs of HBM and checklist of behavior in self-medication in both groups. The data were analyzed by SPSS16 using descriptive and analytical statistical tests.
\end{abstract}

Result: At baseline, there was no significant difference between the mean scores of knowledge, perceptions (self-efficacy, susceptibility, severity, perceived benefits and barriers, self-Efficacy), and prevention of self-medication behavior in both intervention and control groups $(\mathrm{p}>0.05)$; but after the intervention, there was a significant difference between the mean scores of both groups in all variables $(\mathrm{p}<0.001)$. Also, post-test results showed the considerable promotion of perceived barriers scores in the intervention group, especially on simple and fast inaccessibility to physician and high physician expenses.

Conclusion: Educational and promotional intervention based on the health belief model is effective in improving the perceptions and behavior of women in the prevention of selfmedication.

Keywords: Prevention, Self-Medication, Health Belief Model, Women, Health education \& promotion 


\section{Introduction:}

The World Health Organization (WHO) defines self-medication as the selection and use of medicines by individuals without a physician's prescription to treat self-recognized illnesses or symptoms [1]. Self-medication (SM) is a common and global health problem [2] and has been high all over the world, for example, up to $68 \%$ in European countries and $53 \%-76 \%$ among the different populations in Iran [2-4]. It is still a fairly common practice, especially in economically deprived countries. In developing countries, people, especially pregnant women are using both nonprescription and prescription drugs without supervision [5].

Self-medication is a major social, health, and economic problems in many countries, including Iran. Research findings have indicated that a large percentage of Iranian patients practiced Selfmedication before seeking care at public service [2]. A study on self-medication of herbal and chemical medicines in Isfahan showed that $86 \%$ of women had experienced self- medication within the last 6 months [6]. A quantitative study by Jafari et al [4] also revealed an $83 \%$ prevalence of SM among elderly individuals in Iran. Similarly, the meta-analysis performed by Azami Aghdash et al [3] was indicative of a 53\% prevalence of SM in Iran.

The phenomenon of self-medication causes the growth of many problems such as antibiotic and drug resistance, inefficient and prolonged treatment, harmful toxicity and implications, drug dependence, and even sudden death in certain cases [2].

This also results in disruption in the pharmaceutical market, waste of money, and increased per capita of drug use [2]. According to the report of WHO, up to $40 \%$ of therapeutic costs are spent on arbitrary purchase of medicines [7].

There are many factors involved in this public health care problem (self-medication) including sociocultural and socioeconomic characteristics, the previous good experience of treating similar 
illness, the attitude toward disease, non-availability of doctors, prompted by a pharmacist, and the availability of medicinal products $[8,9]$.

Identifying the information source of self- medication may lead to intervention adjustments to reduce the self-medication behavior in society [10]. According to many studies, self-medication is more common among women $[5,8]$. Since women can affect health related behaviors of families, so they can play a role in self- medication; Therefore, targeting this group in the studies on the health system is very crucial [11].

Studies conducted reveal that identifying the effective factors of behavior change, makes it easy to access the change; therefore, learning the proper use of medicines and preventing self-treatment by models which strengthen and identify the factors affecting the behaviors are necessary. For this purpose, researches have used some models to change behaviors. One of these affecting models in health education is the HBM, in which behaviors follow individuals` perceptions, and according to its details, this model has been designed based on the idea of making the individual understand the health threat, so it leads to her behaviors toward health [12]. This model can increase the sensitivity and severity of individuals' perception of self-medication and their self-efficiency to prevent self-medication; and according to the perceived benefits and barriers and guide to action, it modifies their behaviors to healthy behavior or non-self-medication. The current study aimed to investigate the effectiveness of a health promotion intervention and education based on (HBM) model on improving the perceptions and preventive behaviors of self-Medication among women in Tehran, Iran. 


\section{Methods}

Study design

A controlled quasi-experimental intervention survey was conducted among 88 women at selected health institutions of one selected district of Tehran city, Iran. Approval from the Ethical Review Committee of the Shahid Beheshti University of Medical Sciences (SBMU) (Code: IR.SBMU.RETECH.REC.1396.1214) was obtained before starting the study. Written consent was obtained from each participant before conducting the study. Regarding ensuring the secrecy of participants' information; a unique code number was used. They were also informed that they are free to leave the interview at any point.

\section{Recruitment and randomization}

All Iranian women aged 18 years old and above which covered by health institutions of selected Tehran municipality district, and willing to participate in the study were included in this study. Women excluded if they did not want to continue with the research and occurrence of any severe illness for them during the study.

A multi-stage random sampling method was conducted to select the participants. Due to limited time and money, the North of Tehran included in this study. First of all, one district in the North of Tehran was selected by a simple random number table. In the second stage, four health institutions in the selected district chose randomly. In the third stage, two selected health institutions were randomly assigned to the intervention group and another two selected health institutions were randomly assigned to the control group by using the simple random technique. Finally, based on the list of all eligible women covered by selected health institutions and served as a sampling frame, eligible women were randomly assigned into the intervention and control groups, by using the odd and even numbers selection. To control contamination between 
participants, they fill up a questionnaire at different places and selected from different classes. To ensure confidentiality, unique code numbers were given to each participant. Figure 1 shows the flow chart of the study participants in the intervention and control groups.

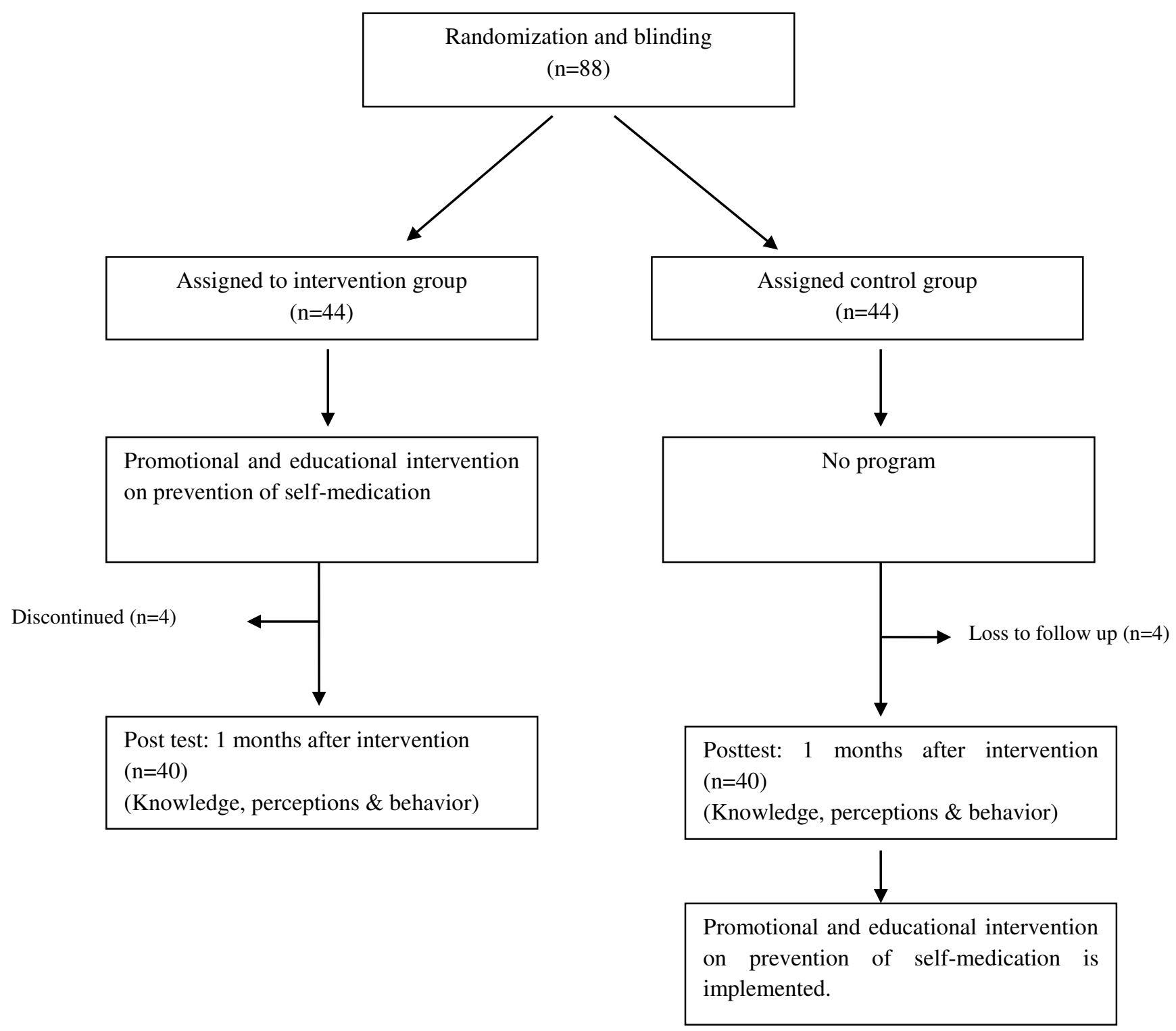

Fig 1. Flow chart of study participants in control and interventions group 


\section{Sample size estimation}

The sample size of this study was calculated based on the Rosner formula [13]. To achieve $80 \%$ power ( $95 \%$ confidence interval), and group differences of 17.8 [14], and the attrition rate of $10 \%$, 44 participants need for each group. The final sample size of this study for both groups was 88 participants. Among those who initially agree to participant in this study, 8 respondents dropped out. As a result, 40 women in the intervention group, and 40 women in the control group completed the study.

\section{Instrument}

A self-administrative questionnaire developed by researchers based on the previous research publications $[14,15]$, and according to the HBM [16]. The content validity of the questionnaire was checked by five experts from the faculty of health, SBMU by calculating the Content Validity Index (CVI) with a value of 0.80 (acceptable). The reliability of the questionnaire was checked by calculating Cronbach's alpha and test-retest among 15 women from another district of Tehran, were not included in the main study (Refer to supplementary file 1). The questionnaire included the following sections:

\section{Socio-demographic characteristics}

This section included 6 questions on demographic specifications including: age, marital status, level of education, family income, working status, and insurance.

\section{Knowledge of self-medication}

Participants' knowledge of self-medication was assessed using 16 items concerning their knowledge. Responses were measured using the nominal scale of "True" and "False". Respondents were given Zero for the wrong answer and 1 for the correct response. The Kappa value for the knowledge part was $(0.80-0.92)$ which is acceptable. 


\section{Perceptions on Self-medication based on Health Belief Model}

The third part evaluated the perceptions (Health belief) of participants by using a self-developed questionnaire. It was included 31 questions related to the sensitivity of self-medication (4 items, score range $0-20$ ), the severity (6 items, score range $0-30$ ), the perceived benefit ( 5 items, score range $0-25$ ), perceived barriers ( 8 items, score range $0-40$ ), and self-efficacy ( 7 items, score range 0-35). Each item scored by Likert Scale starting from 1 "strongly disagree" (1) to 5 "strongly agree". Acceptable Cronbach's alpha values were recorded for sensitivity $(\alpha=0.86)$, severity $(\alpha=$ $0.82)$, benefit $(\alpha=0.70)$, barriers $(\alpha=0.83)$, and self-efficiency $(\alpha=0.88)$. These values were consistent with the previous studies in Iran $[15,17]$.

\section{Cause to action to prevent self-medication}

In this part, there were 6 options for one question on cause to action to prevent self-medication. The participants could choose more than one choice, scores varied from 0 to 6 . These options included: a. physician b. Family members c. Friends, relatives and neighbors d. books and pamphlets e. magazines and publications f. radio and television and other cases.

\section{Behavior towards self-medication}

This part included two parts; in first section included17 items (score range 0-31) that assess the behavior of participants regarding self-medication. Each item was assessed by asking if the respondent ever used medicines arbitrarily or not during the previous month. The Kappa value for behavior towards the self-medication part was $(0.78-0.87)$ which is acceptable. In the second section asked questions about during the last months in which of the disease you used selfmedication. 


\section{Development of intervention}

An educational plan was provided using the constructs of the HBM, the main goal of the present study, and also a codification of the course in three areas of cognitive, attitude, and behavior, in accordance with needs of subjects.

For this purpose, the educational module on prevention of self-medication was developed based on constructs of health belief model, WHO and Food and Drug Organization, Ministry of Health and Medical Education, Iran [18, 19]. The content of the educational module included: improving the knowledge, perceptions \& attitudes, and preventive behavior of self-medication (refer to table 1 for detailed information on the educational module). The content of the educational module also was check and improved by a group of experts including medical doctor, public health specialist, and pharmacist. For checking acceptability and comprehension of the educational module, it was tested among 15 women which not included in the main study.

Table1 Details content of "prevention of self- medication" module.

\begin{tabular}{|c|c|}
\hline $\begin{array}{l}\text { Chapter Content } \\
\text { Preface }\end{array}$ & Content \\
\hline $\begin{array}{l}\text { Chapter 1. Improving the } \\
\text { knowledge of self-medication }\end{array}$ & $\begin{array}{l}\text { - } \quad \text { Definition of self-medication and its types. } \\
\text { - } \quad \text { Storage and maintenance of medicines } \\
\text { - } \quad \text { Medicine addiction and its side effects }\end{array}$ \\
\hline $\begin{array}{l}\text { Chapter } 2 . \quad \text { Improving the } \\
\text { perceptions and attitudes on } \\
\text { Self medication }\end{array}$ & $\begin{array}{l}\text { - The severity of the side effects of self-medication and } \\
\text { everyone's sensitivity. } \\
\text { - Not consume arbitrarily self- medication despite the } \\
\text { possibility of doing so } \\
\text { - The benefits of not consume arbitrarily self- medication } \\
\text { compared to existing barriers }\end{array}$ \\
\hline $\begin{array}{l}\text { Chapter } 3 \text {. Improving the } \\
\text { preventive behavior }\end{array}$ & Prevention of self-medication \\
\hline
\end{tabular}

These medicines were included: Antibiotics, corticosteroids, injective medicines, types of painkillers, sedatives and hypnotics, herbal medicines, vitamins and supplements. 


\section{Intervention}

Health promotion and education intervention procedures were administrated to the intervention group for one month. The intervention group participated in three 90 minutes' sessions in three areas of cognitive, attitude, and behavior which covers all contents of "educational module on prevention of self-medication" in the form of the slide presentation, group discussion, and question and answer. Also, the intervention group watches a short movie (10 minutes) about the side effects of arbitrary antibiotic use, including bacterial resistance, which was designed and displayed in the form of a short story. All the sessions were administered by the main researcher. At the end of the workshop, each participant received a copy of the educational module and CDs.

In this study, in addition to education based on the health belief model, a health promotion method was used to reduce perceived barriers, which included high medical fees and a lack of easy and fast access to the doctor. These barriers were the most frequent barriers to preventing selfmedication. For this purpose, the free medical facilities of a general practitioner were added to the health institutions of the intervention group.

Both groups responded to the validated questionnaires at baseline and one month after the intervention. The control group received one session education about "breast cancer", and they received the "educational module on prevention of self-medication" and watches a short movie after the data collection.

\section{Data Analysis}

The Statistical Package for Social Sciences (SPSS 16) was employed to analyze data. Descriptive statistics include frequency, percentage, mean, and standard deviation were used for both intervention and control groups. Appropriate inferential tests such as independent sample t-test, 
one-way ANOVA, paired T-test, Pierson and Spearman correlation index were used for comparison between and within two groups. The cut-off level for alpha was set at 0.05 .

\section{Results:}

In the current study, the mean age was $44.25 \pm 11.21$ in intervention group and $40.04 \pm 10.65$ in control group. In demographic specifications, most of the subjects in intervention and control groups were: housekeepers $(79.5,68.2 \%)$, married $(84.1,79.5 \%)$, under insurance coverage $(81.1$, $77.31 \%)$, and had high school diploma $(70.5,59.1 \%)$. Therefore, statistically, there was no significant differences among them $(\mathrm{p}>0.05)$.

As can be seen in table 2, according to the independent sample t-test, there was no significant difference between the mean of knowledge, self-efficiency, perceived sensitivity, severity, benefits, barriers, and behavior in both groups before intervention ( $p>0.05)$ (Table2). 
Table 2 Mean score of perceptions, knowledge and behaviour of self-medication in experimental and control groups, before the intervention

\begin{tabular}{|c|c|c|c|c|c|}
\hline \multirow[t]{2}{*}{ variable } & \multicolumn{2}{|c|}{$\begin{array}{l}\text { Experimental } \\
\text { group }\end{array}$} & \multicolumn{2}{|c|}{ Control group } & \multirow[t]{2}{*}{$\begin{array}{c}\text { Before intervention } \\
\text { t-test ( } p \text { value) }\end{array}$} \\
\hline & Mean & SD & Mean & SD & \\
\hline Sensitivity & 15 & 3.43 & 15 & 2 & $\begin{array}{l}\mathrm{p}>0.05 \\
0.75\end{array}$ \\
\hline severity & 20.7 & 4.21 & 20.5 & 4.07 & $\begin{array}{c}\mathrm{p}>0.05 \\
0.79\end{array}$ \\
\hline benefits & 21.3 & 4.91 & 19.5 & 4.48 & $\begin{array}{c}\mathrm{p}>0.05 \\
0.08\end{array}$ \\
\hline barriers & 25.5 & 7.8 & 25 & 5.8 & $\begin{array}{c}\mathrm{p}>0.05 \\
0.77\end{array}$ \\
\hline Self- efficacy & 23.7 & 6.7 & 24.2 & 6.1 & $\begin{array}{l}\mathrm{p}>0.05 \\
0.73\end{array}$ \\
\hline behavior & 22.3 & 3.8 & 20.4 & 6.6 & $\begin{array}{c}\mathrm{p}>0.05 \\
0.11\end{array}$ \\
\hline knowledge & 13.8 & 3.7 & 14.7 & 2.7 & $\begin{array}{c}\mathrm{p}>0.05 \\
0.18 \\
\end{array}$ \\
\hline
\end{tabular}


Table 3 displays the mean score of HBM domains, knowledge and behaviors after intervention. Based on the result the mean score of knowledge, self-efficiency, perceived sensitivity, severity, benefits, barriers, and behavior for the intervention group was higher than control group after onemonth intervention $(\mathrm{p}<0.001)$ (Table 3)

Table 3 Mean score of perceptions, knowledge and behavior of prevention of self-medication in experimental and control groups, after the intervention

\begin{tabular}{lccccc}
\hline variable & \multicolumn{2}{c}{$\begin{array}{c}\text { Experimental } \\
\text { group }\end{array}$} & \multicolumn{2}{c}{ Control group } & \multirow{2}{*}{$\begin{array}{c}\text { After intervention } \\
\text { t-test (p value) }\end{array}$} \\
\cline { 2 - 4 } & Mean & SD & Mean & SD & \\
\hline Sensitivity & 18 & 2.36 & 15 & 3 & $\mathrm{p}<0.001^{*}$ \\
Severity & 25.5 & 3.69 & 21 & 3.85 & $\mathrm{p}<0.001^{*}$ \\
Benefits & 24 & 1.65 & 19.9 & 4.52 & $\mathrm{p}<0.001^{*}$ \\
Barriers & 31.4 & 5.3 & 24 & 5.6 & $\mathrm{p}<0.001^{*}$ \\
Self- efficacy & 29.1 & 3.9 & 24.3 & 5.2 & $\mathrm{p}<0.001^{*}$ \\
Behavior & 27.5 & 3.1 & 20.6 & 6.6 & $\mathrm{p}<0.001^{*}$ \\
Knowledge & 19.2 & 2.5 & 14.8 & 2.7 & $\mathrm{p}<0.001^{*}$ \\
\hline
\end{tabular}

* Level of significant $\mathrm{p}<0.05$

Figure 2 compares mean changes in HBM domains in intervention and control groups. As shown in this figure there was a slight increase in the mean score of benefit from baseline (21.3) to one month after the intervention (24) $(\mathrm{p}<0.001)$. While in the control group, no significant improvement in benefit after one month's follow-up. The figure also indicates most changes related to the mean score of the perceived barrier before and after the intervention. In this way, post-test results show the improvement in the scores of perceived barriers in experimental group, especially regarding lack of easy as well as fast access to doctor from $20.5 \%$ to $45 \%$ and 
considering the high medical fees from $4.5 \%$ to $7.5 \%$. The detailed information of mean changes in HBM domains, knowledge, and behavior of prevention of self-medication in intervention and control groups over time shows in figure 2 . 

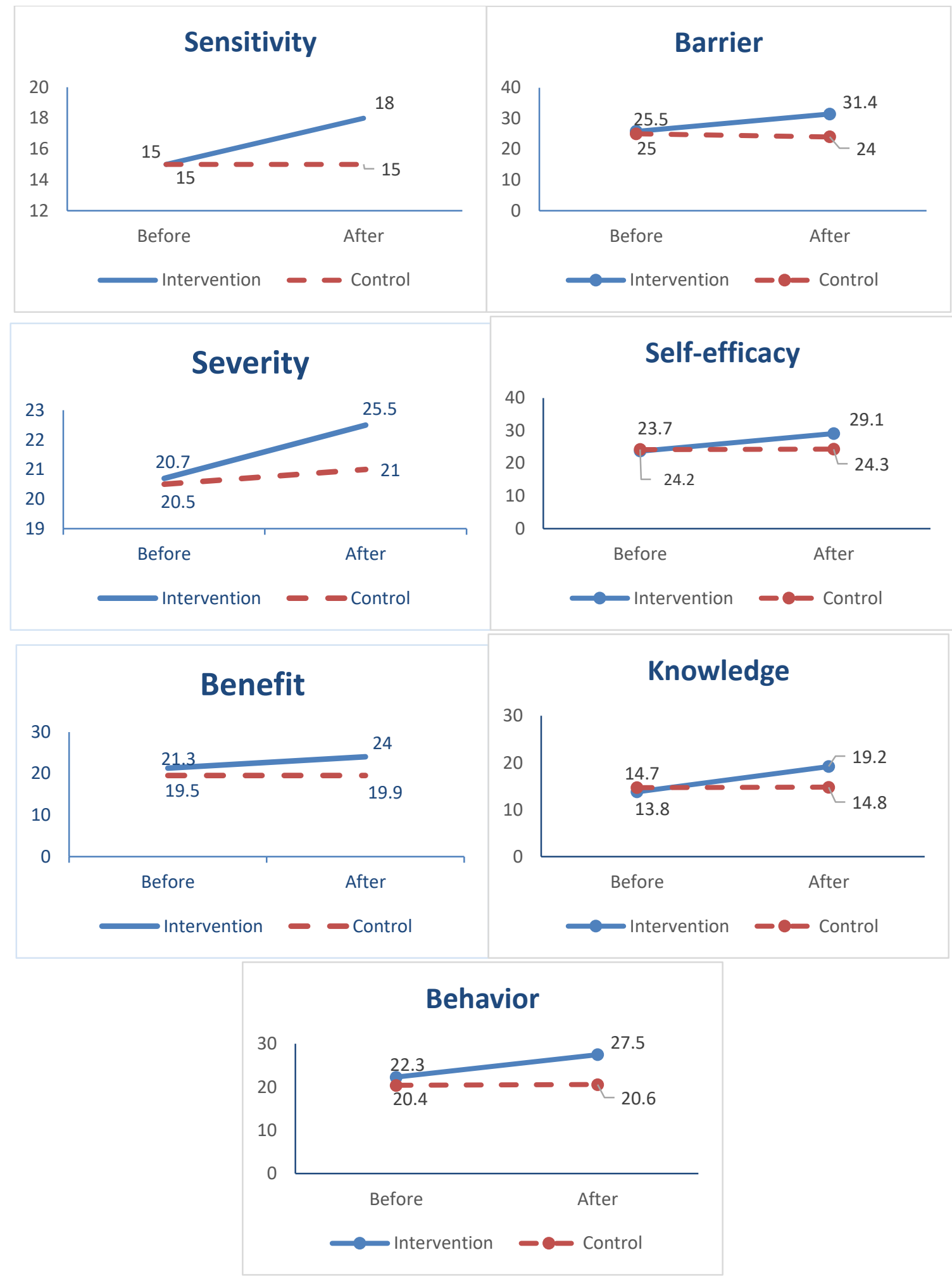

Figure 2. Comparison mean changes in HBM domains, knowledge and behavior of prevention of selfmedication in intervention and control groups over times 
Using Pierson test to evaluate the relation between behavior and knowledge with perceptions demonstrated that there was a significant difference between self-efficiency and knowledge $(\mathrm{r}=0.32, \mathrm{p}=0.04)$, and self-efficiency and behavior $(\mathrm{r}=0.42, \mathrm{p}=0.007)$. Also, this test revealed that there was a significant difference $(\mathrm{p}<0.05)$ between self-efficiency and benefits $(\mathrm{r}=0.41, \mathrm{p}=0.007)$, barriers $(\mathrm{r}=0.50, \mathrm{p}<0.001)$, severity $(\mathrm{r}=0.49, \mathrm{p}<0.001)$ and sensitivity $(\mathrm{r}=0.31, \mathrm{p}=0.04)$, and also between sensitivity and benefits $(\mathrm{r}=0.49, \mathrm{p}<0.001)$, and barriers $(\mathrm{r}=0.58, \mathrm{p}<0.001)$ (Table 4).

Table 4 Evaluating the relation between structures of health belief model and between behavior and knowledge

\begin{tabular}{|c|c|c|c|c|c|c|c|c|}
\hline & & Susceptibility & Severity & Benefits & Barriers & $\begin{array}{l}\begin{array}{l}\text { Self- } \\
\text { efficacy }\end{array} \\
\end{array}$ & Knowledge & Performance \\
\hline \multirow[t]{2}{*}{ susceptibility } & correlation & - & & & & & & \\
\hline & $\mathrm{P}$ & & & & & & & \\
\hline \multirow[t]{2}{*}{ severity } & correlation & 0.22 & - & & & & & \\
\hline & $\mathrm{P}$ & 0.17 & & & & & & \\
\hline \multirow[t]{2}{*}{ benefits } & correlation & 0.49 & 0.19 & - & & & & \\
\hline & $\mathrm{P}$ & $0.001 * *<$ & 0.22 & & & & & \\
\hline \multirow[t]{2}{*}{ barriers } & correlation & 0.58 & 0.12 & 0.21 & - & & & \\
\hline & $\mathrm{P}$ & $0.001 * *<$ & 0.45 & 0.17 & & & & \\
\hline \multirow[t]{2}{*}{ self-efficacy } & correlation & 0.31 & 0.49 & 0.41 & 0.5 & - & & \\
\hline & $\mathrm{P}$ & $0.04 *$ & $0.001^{* *<}$ & $0.007 * *$ & $0.001^{* *<}$ & & & \\
\hline \multirow[t]{2}{*}{ knowledge } & correlation & 0.16 & 0.24 & 0.03 & 0.1 & 0.32 & - & \\
\hline & $\mathrm{P}$ & 0.30 & 0.13 & 0.84 & 0.52 & $0.04^{*}$ & & \\
\hline \multirow[t]{2}{*}{ behavior } & correlation & -0.05 & 0.01 & -0.17 & 0.22 & 0.42 & 0.16 & - \\
\hline & $\mathrm{P}$ & 0.75 & 0.93 & 0.27 & 0.15 & $0.007 * *$ & 0.3 & \\
\hline
\end{tabular}

$* * \mathrm{p}<0.05 ; \mathrm{p}<0.001$ 
Finally, based on the result of current study, the most frequent diseases related to self-medication reported before the intervention in this study in the intervention and control groups, respectively, included: headache (72.7\% and 47.7\%), cold (54.5\% and 40.9\%), vitamins intake (44.2\% and 47.7\%), cough (22.7\% and $15.9 \%)$ and sore throat (20.5\% and $18.2 \%)$.

After the intervention, self-medication was reduced in the mentioned diseases in the intervention group. But in the control group, it even increased. The percentage of self-medication in the intervention and control groups was respectively as follows: headache (40\% and $47.5 \%)$, cold (25\% and $45 \%)$, vitamins intake (22.5\% and $62.5 \%)$, cough (7.5\% and $17.5 \%)$ and sore throat (5\% and $17.5 \%)$.

Furthermore, Post-test results show the improvement in the scores of perceived barriers in the intervention group, especially regarding lack of easy as well as fast access to a doctor from $20.5 \%$ to $45 \%$ and considering the high medical fees from $4.5 \%$ to $7.5 \%$.

Analysis of variance also showed the significant difference between average scores of selfmedication and the educational level in control group after the intervention $(\mathrm{p}=0.03)$. In this case, the mean performance scores in patients with higher education levels were higher. 


\section{Discussion}

The result of this study showed that knowledge, HBM domains (sensitivity, severity, benefits, barriers, self-efficiency), and behavior regarding the prevention of self-medication of participants improve after the intervention. In accordance with the present results, Moghadam`s research on the prevention of the behavior of self-medication among women in Sabzevar city, reported no significant difference between the scores of knowledge, attitude, and performance toward selftreatment in both experimental and control groups, before the intervention. However, after the intervention, a significant difference has appeared in all variables between the two groups [20]. Similarly, a former study on the effectiveness of an educational intervention based on the HBM in preventing high-risk behaviors among pregnant women, reported that three months after the intervention, the scores of knowledge HBM components, and behaviors were significantly better in the intervention group than in the control group [21]. On the other hand, Bayati et al, in the study on pregnant women in Arak, Iran indicated the significant difference between both groups in all variables after educational intervention based on HBM, and the negative behavior of mothers in self-treatment decreased [14]. Therefore, it can be concluded that providing an effective educational intervention, based on the health belief model, can increase these perceptions and behavior.

Generally, significant differences, after the intervention, between both intervention and control groups can be considered as the effective result of educational intervention and education sessions regarding lack of self-treatment which causes the increase of knowledge, perceptions, and behavior in the experimental group.

In the present study regarding the increase of perceived sensitivity, most of the subjects of the intervention group after intervention acknowledged that they may also be at the exposure of self- 
treatment. Accordingly, slides and movies of people who suffered from side effects of selftreatment were used to show the severity of these side effects to attract subjects`attention to health threats and the risk of suffering from other diseases and high treatment fees which are among important factors in increasing the level of perceived severity in subjects. It seems that subjects attention has been attracted to the fact that proper use of medicines leads to a decrease of side effects and faster treatment, which can affect increasing the level of perceived benefits.

The high medical fees, lack of trust in some doctors, and lack of easy and fast access to the doctors are the most prevalent barriers mentioned by subjects of the current study. Similarly, in a former study in Iran, similar to other studies performed in other underdeveloped countries, financial and time constraints have been considered as the most important barriers and the main reason for self -medication [2]. Also in some studies conducted in developed countries like USA, Germany and developing country (Jordan) shows medical and medicine fees, lack of trust in doctors, lack of medical insurance, long waiting hours and difficulty accessing healthcare services were considered as the most important factors or barriers of self-medication [22-24].

A study conducted by Yoshita (2019) among residents of senior-living communities reported, financial and healthcare resources, the severity of the symptoms, experiences with the medication, and relationship with the physician were the most prevalent perceived barriers of self- medication [25]. Perceived barriers are among the most important key factors of the HBM which predicts the subject's behavior [16]. Therefore, details of perceived barriers must be considered as one of the interfering points.

Concerning the results of the current study, it seems that the use of the promotional method of providing free medical services along with education greatly influenced the promotion of selfmedication prevention behavior via helping overcome many of these barriers to self-medication 
prevention behavior, including the high cost of the doctor and lack of easy and quick access to the doctor.

Moreover, designing and showing a short video (10 minutes) to the intervention group was an Innovative method that was used in this study to change the attitude and promote the perceptions of the case group regarding the prevention of self-medication. In this video, the side effects of arbitrary antibiotic use, including bacterial resistance, were designed and displayed in the form of a short story.

In the study of Shamsi, the decrease of perceived barriers and increase of perceived benefits in pregnant women leads to a decrease in self-treatment behavior scores of the subjects under study [26]. In the current study, after the intervention, a significant statistical relation was observed between self-efficiency and benefits, barriers, severity and sensitivity, and also between sensitivity, benefits, and barriers. Therefore, the hypothesis of correlation among details of the health belief model is accepted.

Considering the correlation between self-efficacy and other perceptions of the HBM, it seems that taking action to improve this perception is effective in promoting other perceptions and should be paid more attention to promotional interventions. These relations were also demonstrated in different studies done in Qom [26], and Zarandieh [27] on self-medication. Therefore, in Shamsi`s study, there was an inverted and significant correlation between self-efficacy, perceived barriers, benefits, sensitivity, and self-treatment in the mothers under study [26]. In other researches which using the HBM, such as Norouzi on breast self-examination [28] and Gammage et al., (2011) on the prevention of osteoporosis [29], also the significant relation among severity and sensitivity, behavior with self-efficacy and benefits, and self-efficacy with barriers were observed. Similarly, findings of studies about the SM which were done in Italy [30], and Iran [2] reported, there was a 
significant relationship among the patients' health beliefs and attitudes toward illnesses (especially not taking their illnesses seriously) and their practice of self-medication.

In the present study, a significant relationship among perceived self-efficiency, knowledge, and behavior in preventing the self- medication in the intervention group was observed, which means by growing the knowledge and beliefs of people about the ability to perform preventing behaviors of self- medication, the probability to perform preventing behaviors of self-medication also grows. Similarly, in the study on "Knowledge, attitudes, and practice regarding medication use in pregnant women in Southern Italy", Italian women, those with lower knowledge about the potential risk of using non-prescribed medications during pregnancy, and who need additional information about using the medications in pregnancy were significantly more likely to use medication without prescription during pregnancy [31]. Also in another study on "Predisposing factors to the practice of self-medication in Brazil", the participants with lower medication knowledge, were more likely to engage in inappropriate self-medication [1].

The finding of the current study showed positive association of prevention of self-medication with level of education $(p=0.03)$, which is in line with other studies done in Tanzania [8], Italy [30] and Iran [3]. According to these findings, it seems that a higher level of education is effective in preventing self- medication.

\section{Strengths and limitations}

The strengths of this study were the use of controlled quasi-experimental intervention, and design the educational module in three areas of cognitive, attitude, and behavior based on HBM, appropriate statistical test. And above all, this study is the first study the used the promotional method of providing free medical services along with education, to overcome many of the barriers to self-medication prevention behavior. Moreover, designing and showing a short video on the 
side effects of self-medication to change the attitude of the intervention group regarding the prevention of self-medication, was an Innovative method that has not been used in any other similar study. Among the limitations of this study, self-reporting of the subjects, coordination with the subjects for continuous participation in the classes, completion of the questionnaires, and lack of facilities and educational aids are noteworthy.

\title{
Conclusion
}

The results of the present study indicate the positive effect of health promotion method and education based on the HBM, on increasing the perceptions of sensitivity, severity, barriers, benefits, self-efficacy and behavior of women regarding the prevention of self-medication. On the other hand, there was a significant statistical relation between self-efficacy and perceived perceptions, knowledge and behavior in preventing the self-medication, and also between sensitivity, benefits and barriers. Hence, based on this model, planning the education and promotion intervention along with providing the necessary medical facilities as a treatment to enhance the perceptions and improve the behavior of the other group to prevent self-medication is highly recommended.

\begin{abstract}
Abbreviations
HBM: Health Belief Model; SM: Self-medication; WHO: World Health Organization; SBMU: Shahid Beheshti University of Medical Sciences; CVI: Content Validity Index; SPSS: Statistical Package for Social Sciences.
\end{abstract}

\section{Declarations}

Ethics approval and consent to participate 
Approval from the Ethical Review Committee of the Shahid Beheshti University of Medical Sciences (SBMU) (Code: IR.SBMU.RETECH.REC.1396.1214) was obtained before starting the study. The study was carried out in accordance with relevant guidelines and regulations. Informed consent was obtained from each participant before conducting the study.

\section{Consent for publication}

Not applicable.

\section{Availability of data and materials}

A request for the data and material may be made to the corresponding author of the article.

\section{Competing interests}

The authors declare that they have no competing interests.

\section{Funding}

This study is related to the project No $1396 / 64208$ from student research committee, Shahid Beheshti University of Medical Sciences, Tehran, Iran.

\section{Author Contributions}

NN, MRG, DSH, and MS designed the study. NN collected the data. NN and MA-Z led the data analysis. NN and MA-Z wrote and critically edited the manuscript. All authors read and approved the final manuscript.

\section{Acknowledgment}


This study is related to the project No 1396/64208 from student research committee, Shahid Beheshti University of Medical Sciences, Tehran, Iran. We also appreciate the "student research committee" and "Research \& Technology chancellor" in Shahid Beheshti University of Medical Sciences for their financial support of this study. We would like to thank the selected health institutions and all the participants who were involved in this study.

\section{References}

1. Pons E, Knauth DR, Vigo Á, Mengue SS. Predisposing factors to the practice of selfmedication in Brazil: Results from the National Survey on Access, Use and Promotion of Rational Use of Medicines (PNAUM). PloS one. 2017;12(12):e0189098-e.

2. Fereidouni Z, Kalyani MN. A model to explain self-medication by Iranian people: a qualitative grounded theory study. BMC Public Health. 2019;19(1):1609.

3. Azami-Aghdash S, Mohseni M, Etemadi M, Royani S, Moosavi A, Nakhaee M. Prevalence and cause of self-medication in Iran: a systematic review and meta-analysis article. Iran J Public Health. 2015; 44(12):1580.

4. Jafari F, Khatony A, Rahmani E. Prevalence of self-medication among the elderly in Kermanshah-Iran. Global J Health Sci. 2015;7(2):360.

5. Zewdie T, Azale T, Shimeka A, Lakew AM. Self-medication during pregnancy and associated factors among pregnant women in Goba town, southeast Ethiopia: a community based cross sectional study. BMC research notes. 2018;11(1):713.

6. Sharifirad GH, Pirzadeh A, Azadbakht L. Knowledge and practice in association with selfmedication of nutrient supplements, herbal and chemical pills among women based on Health Belief Model. JRMS 2011; 16(6): 852-853.

7. Skliros E, Merkouris P, Papazafiropoulou A, Gikas A, Matzouranis G, Papafragos C, et al. Self-medication with antibiotics in rural population in Greece: a cross-sectional multicenter study. BMC Fam Pract. 2010;11(1):58.

8. Marwa KJ, Njalika A, Ruganuza D, Katabalo D, Kamugisha E. Self-medication among pregnant women attending antenatal clinic at Makongoro health centre in Mwanza, Tanzania: a challenge to health systems. BMC Pregnancy Childbirth. 2018;18(1):16.

9. Bogale AA, Amhare AF, Chang J, Bogale HA, Betaw ST, Gebrehiwot NT, et al. Knowledge, attitude, and practice of self-medication with antibiotics among community residents in Addis Ababa, Ethiopia. Expert Rev Anti Infect Ther. 2019;17(6):459-66.

10. Du Y, Knopf H. Self-medication among children and adolescents in Germany: results of the National Health Survey for Children and Adolescents (KiGGS). Br J Clin Pharmacol. 2009;68(4):599-608.

11. Rolita L, Freedman M. Over-the-counter medication use in older adults. J. Gerontol. Nurs. 2008;34(4):8. 
12. Sapkota AR, Coker ME, Rosenberg Goldstein RE, Atkinson NL, Sweet SJ, Sopeju PO, et al. Self-medication with antibiotics for the treatment of menstrual symptoms in Southwest Nigeria: a cross-sectional study. BMC Public Health. 2010; 10:610.

13. Rosner B. Fundamentals of Biostatistics. Boston: Duxbury Press; 2006.

14. Bayati A, Shamsi M, Mohammadbeygee A, Tajic R. The effect of education based on health belief Model (HBM) on situation self-medication in mother refer to health centers in Arak city. Shahid Beheshti University of Medical Sciences Journal. 2010;14(6):331-24.

15. Niksadat N, Solhi M, Shojaezade D, Gohari M. Effective factors in prevention of selfmedication based on Health Belief Model in women referring to the health homes in Tehran's 3rd district, 2012. Health Med. 2013; 7:174.

16. Glanz K, Rimer BK, Viswanath K. Health behavior and health education: theory, research, and practice: Jossey-Bass Inc Pub; 2008.

17. Sadeghian Z, Abedi H, Davaridolatabadi E. Self-medication and its Effective Modifiable Factors among Elderly Referred Health Care Centers in Shahr-e-Kord in 2015. Electronic Physician. 2016;8(10):3205-13.

18. World Health Day - 7 April. 2011 [2012]; Available from: http://www.who.int/world-healthday/en/

19. WWW.fda.gov.ir/ nfi

20. Moghadam M, Shojaiezadeh D, Mahmoudi M. Effect of education based on health belief model to prevent the arbitrary use of the drug in women referring to Health Centers sabzevar city. Health Serv. Res. 2013:1888-76.

21. Abbaspour M, Mazloomy SS, Sharifzadeh G, Javadifar E, Kardan M. The effectiveness of an educational intervention based on the health belief model in preventing high-risk behaviors among pregnant women. Mod Care J. 2016;13(4).

22. Warth J, Puth M-T, Tillmann J, Beckmann N, Porz J, Zier U, et al. Cost-related medication nonadherence among over-indebted individuals enrolled in statutory health insurance in Germany: a cross-sectional population study. BMC Health Serv. Res. 2019;19(1):887.

23. Padilla LK. Self-prescription of antibiotics by Latin Americans in Northern Nevada: University of Nevada, Reno; 2010.

24. Al Baz M, Law MR, Saadeh R. Antibiotics use among Palestine refugees attending UNRWA primary health care centers in Jordan: A cross-sectional study. Travel Med Infect Dis. 2018; 22:25-9.

25. Paliwal Y, Gendron TL, Jones RM, Moczygemba L, Nadpara PA, Slattum PW. A qualitative study to understand over-the-counter medication use and decision-making among residents of senior-living communities. Res. Social Adm. Pharm. 2019;15(6):730-7.

26. Shamsi M, Karimi M, Gholamnia Z, Araban M, Kasmaie P. Measuring Health Belief Model constructs in preventive behavior about self-medication in pregnant women in Arak city. Qom UMSJ. 2011;5(3):64-70.

27. Karimy M, Heidarnia A, Ghofranipour F. Factors influencing self-medication among elderly urban centers in Zarandieh based on Health Belief Model. AMUJ. 2011;14(58).

28. Noroozi A, Jomand T, Tahmasebi R. Determinants of breast self-examination performance among Iranian women: an application of the health belief model. J Cancer Educ. 2011; 26(2):365-74. 
29. Gammage KL, Klentrou P. Predicting osteoporosis prevention behaviors: health beliefs and knowledge. Am J Health Behav. 2011; 35(3):371-82.

30. Galesi D, Lombi L. The consumption of conventional and nonconventional medicines in an Italian province: The influence of sociodemographic factors and health beliefs. Int $\mathrm{J}$ Health Serv. 2019;49(1):85-101.

31. Navaro M, Vezzosi L, Santagati G, Angelillo IF, Group CW. Knowledge, attitudes, and practice regarding medication use in pregnant women in Southern Italy. PloS one. 2018;13(6):e0198618. 


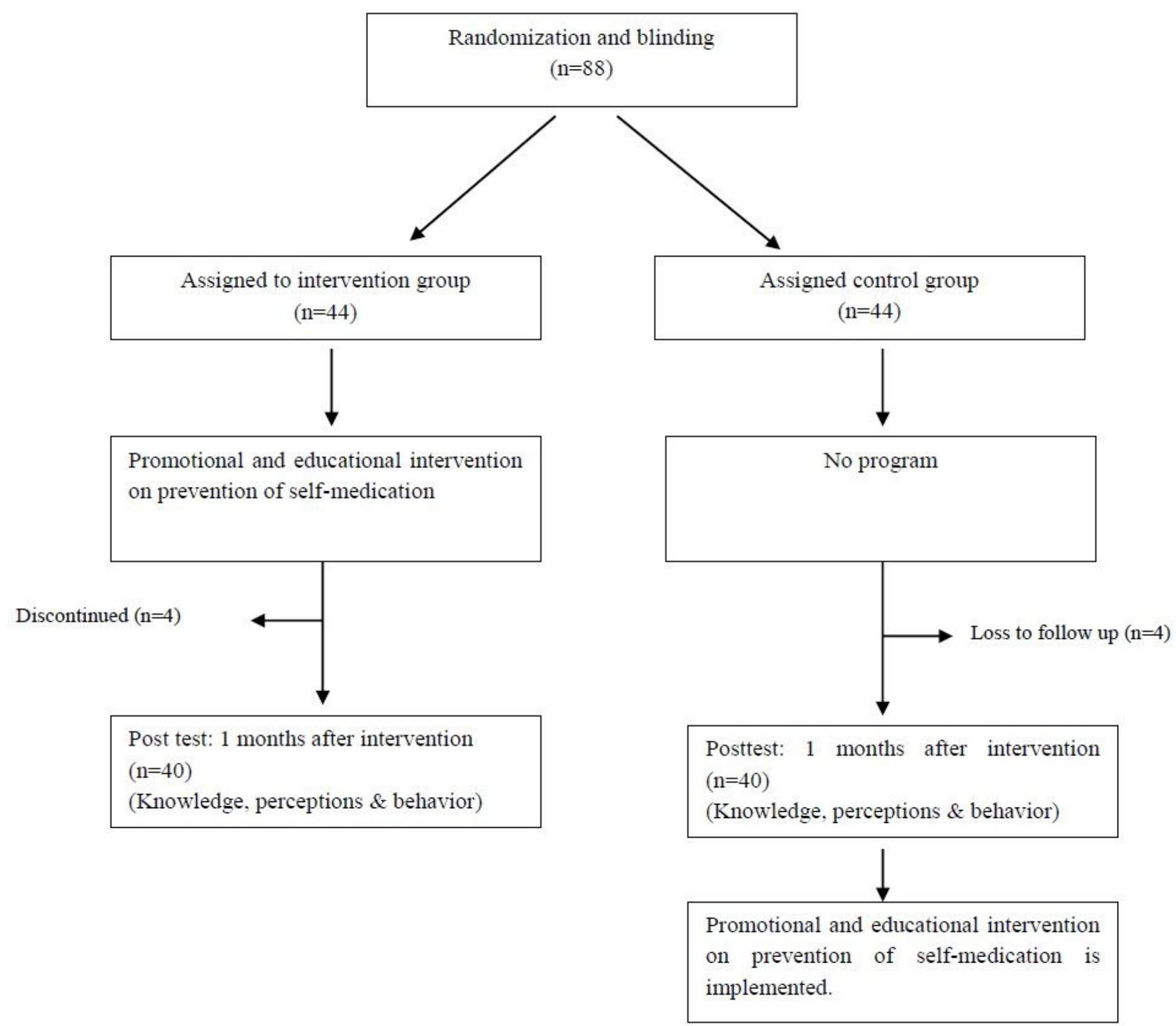

\section{Figure 1}

Flow chart of study participants in control and interventions group 

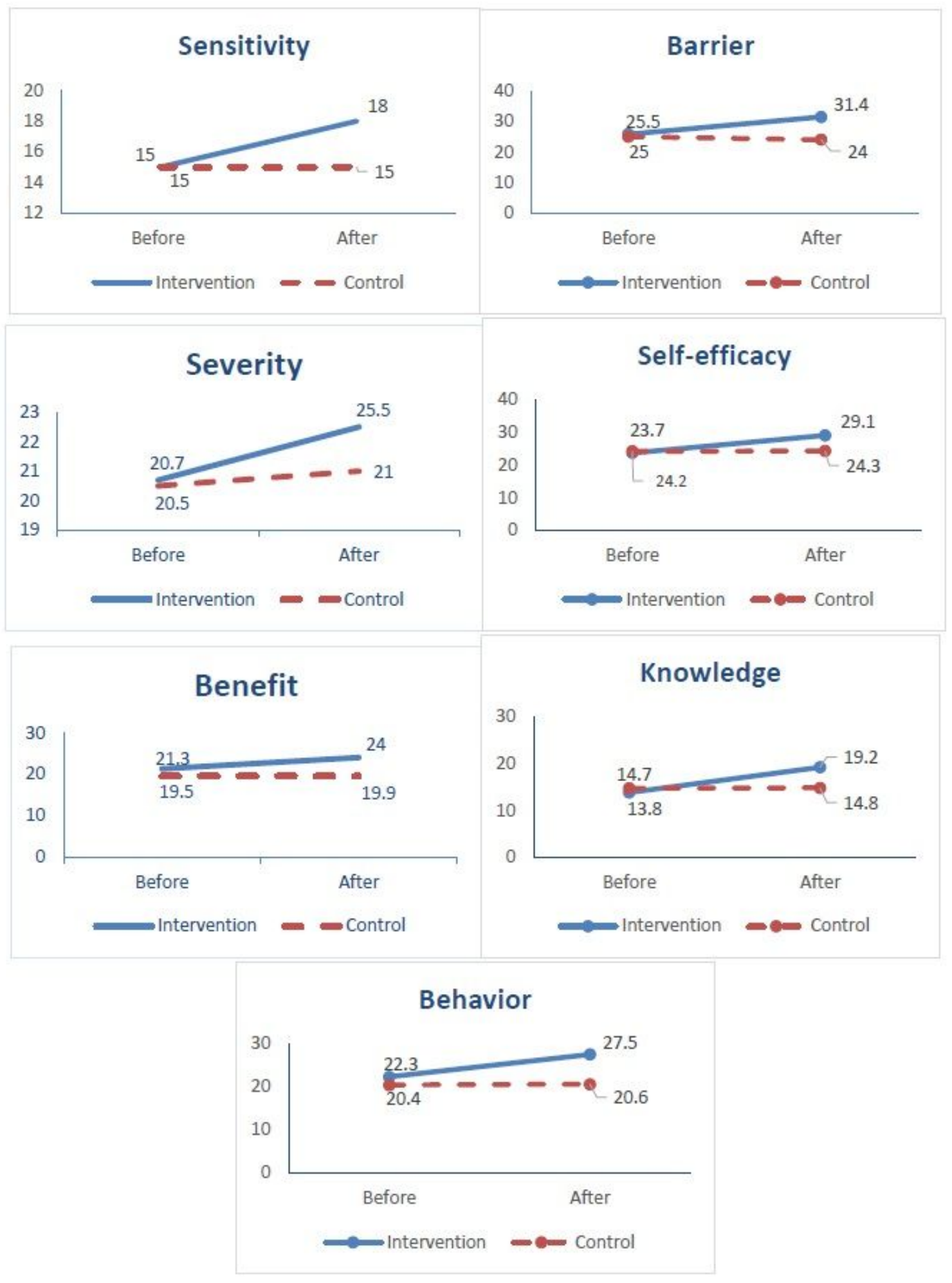

\section{Figure 2}

Comparison mean changes in HBM domains, knowledge and behavior of prevention of self-medication in intervention and control groups over times

\section{Supplementary Files}


This is a list of supplementary files associated with this preprint. Click to download.

- QUESTIONNAIRE.pdf 